\title{
GLOSSARY
}

\section{A glossary for health impact assessment}

\section{J Mindell, E Ison, M Joffe}

Health impact assessments look at the effect on health of policies implemented outside the healthcare sector. A glossary is provided in the following article.

\section{BASIC CONCEPTS}

It has long been recognised that health and its determinants ${ }^{1}$ are strongly influenced by policies outside the healthcare sector, for example, transport, regeneration projects, and housing. In recent years, several countries have introduced health impact assessment (HIA) to try and ensure that potential effects on health are taken into account. It involves identifying disbenefits and benefits to health, interpreting health risk and potential health gain, and presenting this information to aid decision making.

Health impact assessment (HIA): in a consensus paper published by the WHO Regional Office for Europe, HIA is described as "a combination of procedures, methods and tools by which a policy, program or project may be judged as to its potential effects on the health of a population, and the distribution of those effects within the population". ${ }^{2}$ Several other definitions have been proposed. ${ }^{3}$ They generally agree that:

- the aim is to maximise the health gain (and minimise the loss) that would be expected to result from a proposal, and that the latter may or may not have improving health as its aim;

- HIA should be multidisciplinary, intersectoral, and participatory, and include a focus on health inequalities;

- both quantitative and qualitative types of evidence should be used;

- the main values ${ }^{4}$ underlying the conduct of HIA are sustainability, the promotion of health, participation, democracy, equity, ${ }^{1}$ equality (of all stakeholders in the process but in particular of the community ${ }^{1}$ affected), and the ethical use of evidence.

Health inequalities impact assessment (HIIA): suggested by Acheson, ${ }^{5}$ is an HIA with the specific aim of assessing the impacts on the health and wellbeing of a proposal on people in the community who are experiencing health and other inequalities in relation to age, sex, ethnic background, and/or socioeconomic status, to identify whether there is a differential distribution of impacts. The current consensus is that all HIAs should consider inequalities and/or the distribution of potential health effects. ${ }^{2}$

The model of health is the conceptual framework used in an HIA. Typically, the biomedical model, which focuses on disease categories, will be combined with the social or socioeconomic model of health, which has a broader conception and includes "softer" outcomes relating to well- being, according to the nature of a particular proposal and the types of evidence available/ obtainable. The relative balance between the two models of health will normally determine the model of HIA used for the assessment. The biomedical model tends to be quantitative and largely based on epidemiology and toxicology, whereas the social model tends to rely more on qualitative evidence and the social sciences as well as stakeholder knowledge. They have also been referred to as "tight" perspective HIA and "broad" perspective HIA, respectively.

\section{APPLYING HIA}

HIA can be applied to three main levels of proposal: a policy, a programme, or a project; in this paper, we use the term "proposal" to encompass all three, for brevity.

A policy represents the way in which government or an organisation seeks to achieve the objectives it has set. HIA at this level can be strategic, enabling health concerns to be incorporated early on and a "global" view to be taken. In some cases (for example, taxation) there is no lower level at which HIA could be applied.

A programme is a series of related activities that give effect to policy.

A project is a component of a programme, and is a discrete activity often undertaken at a specific location.

HIA at the programme or project level allows health impacts to be assessed that are specific to a particular locality or community. It is more tactical, with aims relating to proposal modification and implementation.

Policy options (comparison of): ideally, an HIA will be able to compare all the possible options that could be under consideration. ${ }^{7}$ This gives policy makers the most explicit information on the health consequences of their actions, and also lends itself to the possibility of integrated assessment. $^{8}$

\section{PROCESS}

Stages: The process of HIA comprises six main stages:

l screening;

2 scoping;

3 appraisal or risk assessment;

4 preparation of report and recommendations;

5 submission of report and recommendations to decision makers;

6 monitoring and evaluation.

Bold type indicates a definition and italic type that the term is described elsewhere in the glossary. 
1 Screening aims primarily to filter out proposals that do not require HIA, so that scarce resources can be targeted on proposals that will benefit from formal assessment. It should be conducted systematically, using either a set of criteria against which proposals are judged, or a screening tool.

2 Scoping (sometimes called "setting the Terms of reference") sets the boundaries for an HIA. It encompasses: the elements or aspects of the proposal to be assessed; the proposal's non-negotiable aspects; aims and objectives of the HIA; values underpinning the HIA; the geographical area covered by proposal implementation; the populations or communities affected; any vulnerable, marginalised, or disadvantaged groups; stakeholders for the HIA and the nature of their involvement; potential health impacts of concern; the resources (human, financial and material) available; the methods to be used; and management arrangements.

Profiling describes the baseline demographics and health status of the affected population(s).

3 In appraisal or risk assessment, the health impacts (positive and negative-benefits and disbenefits) of a proposal are identified by stakeholders and assessors. Many different methods can be used, depending on the model of HIA being used, as well as on timescale or resource constraints. This stage defines the length of the process, from rapid appraisal to comprehensive appraisal.

Rapid appraisal (also called mini-HIA ${ }^{9}$ ) is characterised by the use of information and evidence that is already available or easily accessible. A key element is a half day workshop. While rapid appraisal is comparatively quick and inexpensive, intensive labour is required to prepare for the workshop; also, the attendance of sufficient individuals represents a substantial commitment, if their time is costed. ${ }^{10}$

Comprehensive appraisal (also called maxi-HIA ${ }^{9}$ ) entails the collection of new data. This might include a survey of local residents, a comprehensive literature review, and/or a primary study of health effects of the same proposal elsewhere or, for a concurrent HIA, of the proposal as it is implemented. It usually requires a prolonged and substantial time commitment from a number of people and is resource intensive (unpublished data).

"Desk-top" appraisal is very rapid and is generally undertaken by officers in an organisation to gain a snapshot of the health impacts to inform proposal direction. It is similar to screening but does not have the function of selection.

4 Preparation of the report with its recommendations is the main output of an HIA. It integrates the information obtained from stakeholders during appraisal/risk assessment with the evidence base, findings from other HIAs on similar proposals, and the background information specific to the local community and the relevant geographical area. The assessors should compare stakeholder knowledge with the evidence in the published and grey literature, and account for any discrepancies (which might arise from local conditions and/or circumstances). They should also test the recommendations to ensure that they address the impacts identified, and that the interventions they suggest are effective.

5 Submission of the report and recommendations to decision makers is the primary mechanism by which the outputs from appraisal/risk assessment influence proposal development and/or implementation. For this, it is necessary for the report to be submitted within the schedule set for the relevant decision making process(es), which probably includes specific dates for meetings or deadlines for consultation. It is important to present the report in an accessible format and comprehensible language as the target audience(s) are seldom public health specialists.

6 Monitoring and evaluation has several components:

- Process evaluation sets out to evaluate how successful the process of carrying out the HIA was in practice. It is important as a source of learning, for quality improvement, and as a mechanism of quality assurance.
- Impact evaluation monitors the acceptance of recommendations and the implementation of recommendations once accepted.

- Outcome evaluation monitors indicators and health outcomes after the proposal has been implemented.

Communication and dissemination. Although the decision makers are the primary audience for the report and recommendations, it is important to communicate the main results and recommendations to all stakeholders, especially those who have participated in the process.

Risk communication involves consultation on the risks and consideration of public concerns. ${ }^{12}$

Risk management entails options for avoiding, reducing or treating the risks, consideration of their costs and benefits, and the adequacy of contingency plans. It also includes discussion of how differing perceptions of risk can be mediated and whether future health risks can be predicted. ${ }^{12}$ In the New Zealand and environmental health impact assessment (EHIA) models, monitoring is performed to ensure compliance of a project with the conditions attached to the consent ${ }^{12}$ but most guidance refers to monitoring of health determinants, outcomes, or indicators.

\section{TYPES OF IMPACTS}

Health impacts refer to both positive and negative changes in community health that are attributable to a policy, programme, or project. ${ }^{13}$

Benefits are potential favourable effects on health or its determinants, whether or not intended by a proposal.

Disbenefits are adverse effects on health or its determinants consequent on implementing a proposal. Mitigation is recommending an alternative option or modifications to a proposal to prevent unintended adverse effects (disbenefits).

Opportunities are health benefits that are part of neither the original intentions nor proposals but that provide a chance to improve health and wellbeing by adjusting the design or adding new project components. ${ }^{14}$

The degree to which benefits and disbenefits affect different sections of the community can vary, and thus may ameliorate or exacerbate health inequalities.

A hazard has the potential to cause harm; the risk is the likelihood of that occurring.

\section{TIMING}

A prospective HIA takes place before proposal implementation, and ideally before the proposal is in its final form. To be influential, the HIA needs to be carried out early enough to have an effective input into the decision making process, but late enough that the proposals are sufficiently firm to enable an assessment.

A concurrent HIA is carried out during the implementation of a proposal, and may be of long duration, for example, several years, involving the monitoring of changes in health determinants and possibly in health status. The aim is to identify changes as they occur, which is important if a proposal has some potentially serious health impacts that are unknown or uncertain, because the HIA enables prompt action to be taken. A secondary aim is to evaluate the accuracy of predictions made during a related prospective HIA undertaken previously.

A retrospective HIA is carried out after a proposal has been implemented. It aims to identify the actual impacts on health outcomes after implementation. It differs from evaluation, which monitors the extent to which the proposal's objectives were achieved. ${ }^{15}$ While it is unable to influence the intervention, the HIA can suggest additional actions that may now be required. It can also make a contribution to the evidence base, thereby informing similar proposals in future. 


\section{PEOPLE INVOLVED IN HIA}

Stakeholders are people involved in or affected by proposal development and implementation, drawn from public, private and voluntary sectors, and the communities or groups affected.

Key informants are stakeholders whose roles and/or standing in a community mean that they have experience, knowledge, or information of relevance to the proposal.

Assessors are the practitioners who undertake primarily the appraisal or risk assessment, and the preparation of the report and recommendations.

A steering and/or management group is often appointed to oversee the process and outputs of an HIA, and comprises representatives from key stakeholder organisations and, ideally, representatives from the communities affected. It sometimes includes one or more of the decision makers.

Decision makers are the people who have control over the final content of the proposal, including the extent to which it is influenced by the HIA. They receive the report and recommendations. They may also be involved in the HIA process, and in some instances may be the same body as the steering group.

Community involvement entails the full and active participation of the communities affected as stakeholders. This is one of the values underlying HIA, often referred to as "equality". ${ }^{2}$ Community involvement can be difficult to achieve, particularly when trying to ensure representativeness of views, especially from "hard to reach" groups, but it is important to obtain the perspectives of at least some of the community affected. In some cases, HIAs have been led by a community. Some HIAs have been, and continue to be, undertaken without community involvement. This can be valid when the proposal is at a very early stage of development; when public consultation has occurred and the results are included as components of the appraisal/risk assessment; or during training and capacity building in organisations/ partnerships

Ownership of the HIA process and/or outputs is one factor that determines the success of an HIA and the influence any outputs might have. The degree of ownership tends to vary with the level of involvement. The key to ownership of the process is appropriate and effective involvement of relevant stakeholders. A sense of ownership of the outputs, which may be dependent on ownership of the process, will influence the level of commitment to implementing them. Greater ownership is often achieved when stakeholders have or are given some control or influence over the process and/or the outputs.

\section{MATERIALS TO SUPPORT THE CONDUCT OF HIA}

An HIA tool provides the user with a systematic framework, which has been validated or piloted, to support decision making at various stages in the HIA. The contents of different tools will vary. Currently, most tools have been developed to support practitioners during two stages of HIA: screening, and appraisal or risk assessment.

Checklists are lists of questions or salient points that act as triggers or aide memoires when undertaking certain tasks for an HIA.

Guidelines are systematically developed statements to support practitioners during the process of HIA.

Toolkits are a resource containing at least one tool, plus principles of HIA, guidance on the process, and, possibly, a digest of key references from the evidence base.

\section{EVIDENCE BASE}

Rapid review for HIA is usually conducted in a few days, and tends to be based on other reviews, which may not be systematic or up to date and frequently have not considered confounding or the likelihood of causality. ${ }^{16}$ Such reviews therefore may not be an objective summary of the primary evidence from good quality studies.

Systematic review was described in an earlier glossary. ${ }^{17} \mathrm{~A}$ qualitative systematic review summarises the primary investigations without statistical pooling. Quantitative systematic review is synonymous with meta-analysis. ${ }^{17}$

Primary sources are reports of original studies or the raw data. Secondary sources are reports that quote other people's studies; these may be reviews.

Grey literature refers to reports not published in scientific journals. There are three problems: identifying grey literature, as few such reports are indexed on nationally or internationally accessible catalogues or databases; obtaining copies; and assessing the rigour of the work. Evidence useful in HIA comes from epidemiology and policy analysis but also from retrospective or concurrent assessment of similar interventions. Such HIAs are predominantly published as internal reports or other grey literature.

Off the shelf reviews: this refers to the provision of evidence in a readily available form, providing accurate information and facilitating timeliness.

\section{TECHNICAL METHODS}

Risk assessment was defined in 1983 as "the use of the factual base to define the health effects of exposure of individuals or populations to hazardous materials and situations." 1819 It is generally applied in situations where there is good information about a system..$^{20}$ It is used primarily for assessing the impact of chemicals on human health ${ }^{21}$ and to set standards limiting exposure. ${ }^{22}$ While it was originally applied to the toxic effects of chemical exposures, it can in principle be extended to any situation where both the dose-response characteristics and exposure profiles can be estimated. Risk assessment is a standard four stage procedure ${ }^{19}$ in which three elements are combined to characterise the existing risk.

1 Hazard identification involves identifying the types of health effect that a particular exposure can cause.

2 The "dose-response" assessment quantifies this: for a given level of exposure, a certain effect (or probability of an effect) will result. In practice, this is seldom a dose in the familiar sense, which applies to an individual, but is an ambient level to which the population is exposed. These are derived from the scientific literature in the fields of epidemiology and/or toxicology.

3 Exposure assessment identifies the specific agent(s), determines the route of exposure, and quantifies the amount and duration of exposure. ${ }^{22}$

4 Risk characterisation combines these three elements to estimate the burden of disease attributable to the current exposure.

Modelling is a method of simplifying reality that retains the most important features for the purpose in hand. There are many varieties of model. Some models provide a structure to organise different types of information, for example, the DPSEEA and PRAM models. Another type is a mathematical or statistical model, which aims at quantification and/or prediction; in the context of HIA, this would be the health effects that would be expected to result from a particular intervention.

The DPSEEA model (pronounced "deep sea") distinguishes three stages of antecedents of exposure (in the context of environmental health).$^{23}$ Driving forces are the factors that motivate and push the environmental processes, such as population growth, economic or technical development, or policy interventions. These generate PRESSURES (occupation, production, consumption), which change the state of the environment, generating new environmental hazards. EXPOSURE is not automatic, but when present leads to effects, to prevent which, AстIONs are taken. ${ }^{24}$ DPSEEA can be used to 
quantify health impacts ${ }^{25}$ or as a framework for suggesting modifications to proposals.

Health impact analysis is a purely quantitative approach that uses a decision analysis framework to integrate mathematical models of the dispersal of industrial pollutants into the environment with population health models. Although proponents claim a transparency in decision making based on this analytical approach because of the explicit outcomes modelled, with production of the "best" option, it can be used only where there is extremely complete quantitative evidence or restrictive assumptions.

PRAM (Policy/Risk Assessment Model) is a variant of the standard risk assessment model, but focuses on differences. Of the first three elements in risk assessment, the level of exposure is the one that is most susceptible to variation, and, in particular, is subject to alteration in response to different policy options. The PRAM model relates the interventionderived change in exposure(s), both intended and unintended, to the expected change in the existing risk, giving the health gain (or health loss).

Economic assessments, such as cost-benefit, costeffectiveness, or cost-utility analysis, are sometimes advocated. These terms are defined in an earlier glossary. ${ }^{26}$ They first require assessment of the health impacts so that the impacts can be costed or valued. The first UK government publication on HIA, Policy Appraisal and Health, ${ }^{27}$ considered only economic appraisal, which is still the main approach taken in the regulatory impact assessment required in England. However, properly conducted comprehensive costbenefit analyses are the exception. ${ }^{28}$

\section{RELATED TYPES OF ASSESSMENT}

Risk assessment: see above.

Environmental Impact Assessment (EIA) was initiated by the National Environmental Policy Act (NEPA) in 1969 in the USA,${ }^{29}{ }^{30}$ and has since been introduced widely throughout the world. An Environmental Impact Statement (EIS) is the summary of the results of an EIA. A draft EIS is made available for the public consultation process, after which a final version is prepared, and this forms part of the subsequent decision making process. ${ }^{31}$ EIA is generally carried out at a project level. In principle, consideration of human health outcomes should form part of the assessment but this is frequently omitted or appraised in a manner that is not considered satisfactory by public health specialists (A-B Kobusch, et al, 14th IAIA Conference, Quebec, 1994 and references $^{32-34}$ ). However, an EIA can provide data that are useful for health, for example, on air pollution. The results of a proposal on determinants of health (for example, air pollution) are often referred to as effects, with the consequent results on health being called impacts. Limitations of EIA are that project level assessment may be too late in the process to influence broader policy, and the responsibility for EIA is taken by the proponent of the project, so that its independence may be compromised.

Environmental Health Impact Assessment (EHIA) has been proposed, which explicitly includes consideration of health outcomes within the framework of an Environmental Impact Assessment, to address the historical neglect of health in EIA. ${ }^{34}$ However, linking health to EIA has the drawback that some proposals may have implications for health and its determinants yet would not trigger an EIA, either because it is not statutorily required or when there are not considered to be any potential environmental impacts.

Whereas EIA refers to single projects, Strategic Environmental Assessment (SEA) refers to policies, plans and programmes. Compared with an EIA of a local project, the environmental impacts considered are more general, relating to global and regional impacts, but less detailed. The objectives of SEA are to ensure the full consideration of other policy options, including the "do nothing" option, at an early stage; enable consistency across different policy sectors, thereby facilitating trade offs; ensure that more complex, distal, and unintended consequences are considered, so that adverse impacts can be prevented; assess the environmental impact of policies without an overt environmental dimension; and to include environmental as well as economic and social concerns in decision making. ${ }^{35}$

Social impact assessment (SIA) is concerned with estimating prospectively the likely social consequences of a specific policy or government actions. ${ }^{29}$

\begin{abstract}
"By social impacts we mean the consequences to human populations of any public or private actions that alter the ways in which people live, work, play, relate to one another, organize to meet their needs, and generally cope as members of society." The Interorganizational Committee on Guidelines and Principles, $1994^{29}$
\end{abstract}

SIA resembles EIA both in process and in the assumption that its purpose is to identify potential adverse impacts in advance in order to mitigate them. ${ }^{29}$ In the USA it is usually carried out as part of an EIA. SIA usually includes public involvement ${ }^{36}$ and consideration of the distribution of impacts in the population and the effects on vulnerable groups. ${ }^{29}$ The main impacts considered are population characteristics, community and institutional structures, political and social resources, individual and family changes, and community resources. ${ }^{29}$

Integrated assessment: HIA is often not the only type of assessment that is indicated. Typically, the officials who are responsible for developing the proposals for an intervention are faced with the need to assess the proposal for several major types of impact, for example, social, economic, environmental, and/or health. This could involve a formal EIA or SEA, and/or $S I A$, but it could also include for example assessing the potential impact on gender relations, small businesses, etc.

\section{MAGNITUDE OF IMPACT}

As an HIA aims to assess how a population's health status would be affected by the implementation of a proposal, it has an affinity with certain concepts that are being developed by the WHO.

The burden of disease is the total quantity of ill health caused by a particular disease or risk factor. WHO have a programme that estimates this for the main causes of mortality and major morbidity, measured using "disability adjusted life years" or DALYs. ${ }^{37}$ The attributable health impact is similar: the amount of ill health that can be attributed to a particular risk factor.

The achievable health impact (or avoidable burden of disease) is the change in health status that would be expected to follow a specified change in the level of a risk factor, in relation to an intervention.

\section{FURTHER INFORMATION}

A number of other terms encountered in health impact assessment have been defined in earlier glossaries in this series: causality, ${ }^{16}$ community, ${ }^{1}$ determinants of health, equity, ${ }_{1}^{1}$ health inequalities and health inequities, ${ }^{38}$ the Precautionary principle, ${ }^{39}{ }^{40}$ and values. ${ }^{4}$

Guidance on commissioning or conducting health impact assessment can be found in a number of publications ${ }^{6441-45}$ and on the internet. ${ }^{104647}$

\section{ACKNOWLEDGEMENTS}

We thank Caron Bowen of the London Health Observatory for helpful comments on an earlier version of this glossary. 


\section{Authors' affiliations}

J Mindell, $\mathbf{M}$ Joffe, Department of Epidemiology and Public Health, Imperial College London, London, UK

E Ison, The Institute of Health Sciences, Oxford, UK

\section{REFERENCES}

1 Starfield B. Basic concepts in population health and health care. $J$ Epidemiol Community Health 2001;55:452-4.

2 WHO European Centre for Health Policy, eds. Health Impact Assessment. Main concepts and suggested approach. Gothenburg Consensus Paper, December 1999. Copenhagen: WHO Regional Office for Europe, 1999

3 Mclntyre L, Petticrew M, eds. Methods of health impact assessment: a review. Glasgow: MRC Social and Public Health Sciences Unit, 1999. http://www.msoc-mrc.gla.ac.uk/Reports/PDFs/Occasional-Papers/ OP-002.pdf (accessed 29 Jan 2003).

4 Weed DL, McKeown T. Ethics in epidemiology and public health I. Technical terms. J Epidemiol Community Health 2001;55:855-7.

5 Acheson D, chair. Report of the independent inquiry into inequalities in health. London: TSO, 1998. http://www.official-documents.co.uk/ document/doh/ih/ih.htm (accessed 29 Jan 2003).

$6 \mathrm{Kemm}$ JR, ed. Developing health impact assessment in Wales. Better health, better Wales. Cardiff: Health Promotion Division, National Assembly for Wales, 1999.

7 Joffe $M$, Mindell J. A framework for the evidence base to support health impact assessment. J Epidemiol Community Health 2002;56:132-8.

8 Mindell J, Joffe M. Health Impact Assessment in relation to other forms of assessment. J Public Health Med 2003;25:107-12.

9 Parry J. Prospective health impact assessment: piffalls, problems, and possible ways forward. BM 2001;323:1177-82.

10 Ison E, ed. Rapid appraisal tool for health impact assessment in the context of participatory stakeholder workshops. Commissioned by the Directors of Public Health of Berkshire, Buckinghamshire,

Northamptonshire and Oxfordshire. London: Faculty of Public Health Medicine, 2002

11 Reference withdrawn

12 Public health commission, eds. A guide to health impact assessment. Wellington: Public Health Commission, 1995.

13 Birley M, Peralta GL. Health impact assessment of development projects. In: Vanclay F, Bronstein DA, eds. Environmental and social impact assessment. Chichester: Wiley, 1995

14 Konradsen $F$, Chimbari $M$, Furu $P$, et al. The use of health impact assessments in water resources development: a case study from Zimbabwe. Impact Assessment 1997:15:55-72.

15 Milner S, Marples G, eds. Policy appraisal and health project. Newcastle Health Partnership, Phase 1 - a literature review. Newcastle: University of Northumberland at Newcastle, 1997

16 Susser M. Glossary: causality in public health science. J Epidemiol Community Health 2001;55:376-8.

17 Delgado-Rodríguez M. Glossary on meta-analysis. J Epidemiol Community Health 2001;55:534-6.

18 National Research Council and Committee on the Institutional Means for Assessment of Risks to Public Health. Risk assessment in the Federal Government: managing the process. Washington, DC: National Academic Press, 1983.

19 Samet JM. Risk assessment and air pollution. In: Holgate ST, Samet JM, Koren HS, et al, eds. Air pollution and health. London: Academic Press, 1999

20 Deville A, Harding R, eds. Applying the precautionary principle. Sydney: The Federation Press, 1997.

21 Eyles JD. Health, environmental assessments and population health: tools for a complex process. Can J Public Health 1999;90:S31-4.

22 Hertz-Picciotto I. Epidemiology and quantitative risk assessment: a bridge from science to policy. Am J Public Health 1995;85:484-91.
23 Corvalán C, Briggs D, Zielhuis G, eds. Decision-making in environmental health. London: E\&FN Spon, 2000.

24 Briggs DJ, Wills J. Presenting decision-makers with their choices: environmental health indicators. In: Briggs DJ, Stern R, Tinker TL, eds. Environmental health for all. Risk assessment and risk communication for National Environmental Health Action Plans. Proceedings of the NATO Advanced Research Workshop on inclusive approaches to risk assessment and priority setting for National Environmental Health Action Plans, Ostrava, Czech Republic, 15-20 December 1997. Dordrecht, the Netherlands: Kluwer Academic Publishers, 1999.

25 Fehr R, Lebret E, Ackermann-Liebrich $U$, et al. Integrated environmental health impact assessment of transport policies and projects. Draft, 18.01.1999. Biefeld: LOGD, 1999.

26 Shiell A, Donaldson C, Mitton C, et al. Health economic evaluation. J Epidemiol Community Health 2002;56:85-8.

27 Department of Health. Policy appraisal and health. London: HMSO, 1995.

28 Appleby J. Health impact assessments: desirable but difficult? In: Health Impact Assessment: report of a methodological seminar. London: Department of Health, 1999

29 Interorganizational Committee on Guidelines and Principles. Guidelines and principles for social impact assessment. Impact Assessment 1994;12:107-52.

30 Joffe $\mathbf{M}$, Sutcliffe J. Developing policies for a healthy environment. Health Prom Int 1997;12:169-73.

31 Lee N. Environmental impact assessment: a review. Applied Geography 1983;3:5-27.

32 Canter LW, eds. Health risk impacts in EISs. Oklahoma: Environmental and Ground Water Institute, University of Oklahoma, 1990.

33 Sutcliffe J. Environmental impact assessment-a healthy outcome? Project Appraisal 1995; 10:113-24.

34 Birley M, Boland A, Davies L, et al, eds. Health and environmental impact assessment. An integrated approach. London: Earthscan Publications, 1998.

35 Therivel R, Wilson E, Thomson S, et al, eds. Strategic environmental assessment. London: Earthscan Publications, 1992.

36 Banken R. From concept to practice: including the social determinants of health in environmental assessments. Can J Public Health 1999;90:S27-30.

37 Ezzati $M$, Lopez AD, Rodgers $A$, et al. Selected major risk factors and global and regional burden of disease. Lancet 2002;360:1347-60.

38 Kawachi I, Subramanian SV, Almeida-Filho N. A glossary for health inequalities. J Epidemiol Community Health 2002;56:647-52.

39 Bettcher D, Lee K. Globalisation and public health. J Epidemiol Community Health 2002;56:8-17.

40 McKeown RE, Weed DL. Ethics in epidemiology and public health II. Applied terms. J Epidemiol Community Health 2002;56:739-41.

41 Scott-Samuel A, Birley M, Ardern K, eds. The Merseyside Guidelines for Health Impact Assessment. Liverpool: Merseyside Health Impact Assessment Steering Group, 1998. http://www.liv.ac.uk/ mhb/ publicat/merseygui/index.html (accessed 29 Jan 2003).

42 Conway L, Douglas M, Gavin S, et al, eds. HIA piloting the process in Scotland. Glasgow: SNAP, 2000. http://www.gla.ac.uk/external/ ophis/PDF/hia.pdf (accessed 29 Jan 2003).

43 Elliott I, ed. Health impact assessment: an introductory paper. Dublin: The Institute of Public Health in Ireland, 2001

44 Cave B, Curtis S. Health impact assessment for regeneration projects. Vol I A practical guide. London: East London and The City Health Action Zone, 2001.

$45 \mathrm{Kemm}$ J, Parry J, Palmer S, eds. Health impact assessment: concepts, theory, techniques and applications. Oxford: OUP (in press).

46 Ison E, ed. Resource for health impact assessment. London: NHS Executive London, 2000. http://www.londonshealth.gov.uk/ allpubs.htm\#HIAResource 1 (accessed 29 Jan 2003).

47 Health Development Agency. HIA gateway. http:// www.hiagateway.org.uk 